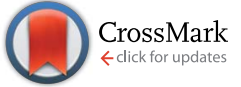

Cite this: RSC Adv., 2017, 7, 8994

\title{
Accelerated simulation of the degradation process of poly(arylene ether ketone)s containing alkylsulfonated side chains used as a proton exchange mmembrane $\uparrow$
}

\begin{abstract}
Dong Liu, ${ }^{a}$ Jiamin Li, ${ }^{a}$ Jiangpeng Ni, ${ }^{a}$ Xiongzhi Xiang, ${ }^{a}$ Bin Liu*ab and Lei Wang*ab
Synthesis of poly(arylene ether ketone)s containing alkylsulfonated side chains (SPAEKs) has continued in recent years because of their numerous advantages when used as proton exchange membranes (PEMs). Although the oxidative stabilities of SPAEKs have been widely characterized in Fenton's reagent, few investigations have reported the oxidative degradation of the membranes, which is critical to the durability of PEMs. In this work, the oxidative degradation of SPAEKs was carefully studied through analysis of the proton conductivity, ${ }^{1} \mathrm{H}$ NMR and FT-IR spectra, elemental composition, molecular weight $\left(M_{w}\right)$, thermal properties, and morphology in a simulated fuel cell environment. The oxidative degradation was mainly ascribed to the cleavage of the main polymer chain, and the excellent properties of the membrane were maintained before it began to break into pieces.
\end{abstract}

Received 3rd December 2016
Accepted 25th January 2017

DOI: 10.1039/c6ra27707a

rsc.li/rsc-advances our group prepared highly branched poly(arylene ether ketone)s containing alkylsulfonated side chains (SPAEKs) as PEMs. The introduction of flexible alkylsulfonated side chains greatly increased the oxidative stability and mechanical properties of the membranes. ${ }^{6}$

In view of the good durability of side chain-type polymers, it is of great importance to understand the oxidative degradation process of the membranes. Several studies have been carried out to experimentally explore the degradation mechanism of PEMs. Maruyama et al. found that hydrogen peroxide can attack the polymer chain to form an intermediate during the fuel cell reaction. ${ }^{12}$ Perrot et al. proposed a mechanism in which degradation proceeded through the addition of a hydroxyl radical to the aromatic ring of sulfonated poly(aryl ether ketone) s. ${ }^{13}$ Lawrence et al. proved that PEMs undergo an unzipping scission during oxidative attack. ${ }^{14}$ Uegaki et al. studied individual radical-induced reactions using $\gamma$-rays and demonstrated that degradation is initiated by radicals. ${ }^{15}$ Despite these proposed degradation mechanisms, there is still not enough evidence supported by experimental data to clearly describe the detailed degradation process, especially for polymers containing flexible alkylsulfonated side chains. ${ }^{\mathbf{1 6 - 1 8}}$

In this work, SPAEKs were successfully synthesized. Three chemical degradation processes were possible during the accelerated oxidative degradation tests of the membrane. As shown in Scheme 1, polymer degradation could occur on (i) the main polymer chain, Section A; (ii) the linker between the main chains and side chains, Section B; or (iii) the sulfonic acid groups, Section C. To study the degradation process of SPAEK, a detailed study of the oxidative degradation of SPAEKs was
${ }^{a}$ Shenzhen Key Laboratory of Polymer Science and Technology, College of Materials Science and Engineering, Shenzhen University, Shenzhen 518060, China. E-mail: wl@szu.edu.cn; bliu@szu.edu.cn

${ }^{b}$ Guangdong Research Center for Interfacial Engineering of Functional Materials, Shenzhen University, Shenzhen 518060, China

$\dagger$ Electronic supplementary information (ESI) available. See DOI: $10.1039 / \mathrm{c} 6 \mathrm{ra} 27707 \mathrm{a}$ 
(a) Section C: Sulfonic acid group

.

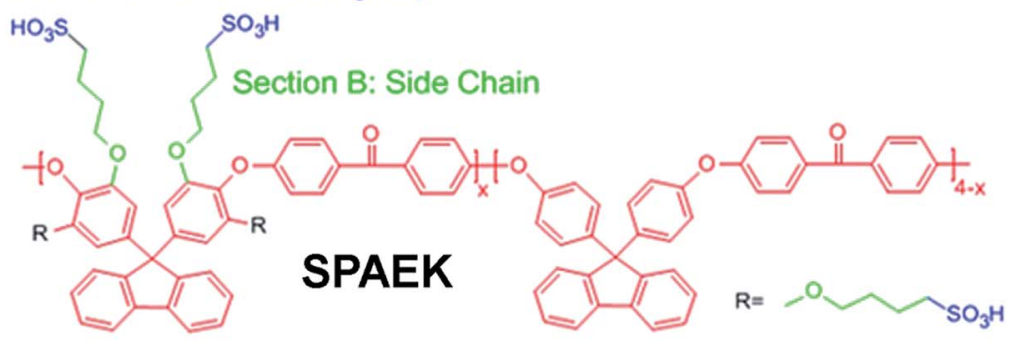

Section A: Main Chain

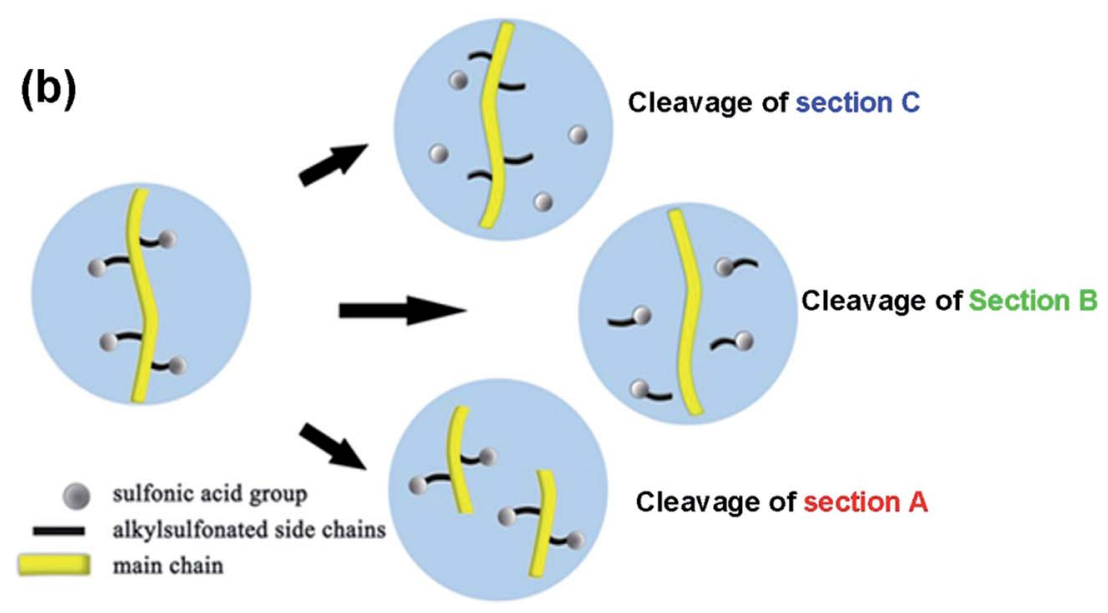

Scheme 1 (a) Three possible cleavage sections of SPAEK; (b) graphical representation of the possible degradation process.

performed, including analysis of the proton conductivity, ${ }^{1} \mathrm{H}$ NMR and FT-IR spectra, elemental composition, molecular weight $\left(M_{\mathrm{w}}\right)$, thermal properties, and morphology, after treatment in an accelerated simulated PEMFC environment.

\section{Experimental}

\subsection{Materials}

Fluorenone, dimethyl sulfoxide (DMSO), 2,6-dimethoxyphenol, boron tribromide $\left(\mathrm{BBr}_{3}\right)$, dimethylacetamide (DMAc), 4,4'difluorobenzophenone (DFBP), dichloromethane, 1,4-butane sultone, beta-mercaptopropionic acid, and phenol were purchased from Energy Chemical and used without further purification. Prior to use, toluene, DMAc and DMSO were immersed in $4 \AA$ molecular sieves, and anhydrous potassium carbonate was powdered and then dried at $300{ }^{\circ} \mathrm{C}$ in a furnace for $24 \mathrm{~h}$. All other chemical reagents and solvents were used as received.

\subsection{Membrane preparation}

All of the polymers were synthesized according to a modified method in the literature, ${ }^{19}$ and the detailed synthetic procedure is presented in the (ESI $\dagger$ ). The synthesized SPAEKs were easily dissolved in DMAc (10-15 wt\% solution) by stirring at room temperature. The solution was filtered, poured into an extremely flat dish, and dried at $60^{\circ} \mathrm{C}$ for $24 \mathrm{~h}$. Membranes with an average thickness of $70 \mu \mathrm{m}$ were obtained. To convert $\mathrm{Na}^{+}$to $\mathrm{H}^{+}$, the resultant membranes were soaked in a $2.0 \mathrm{M} \mathrm{H}_{2} \mathrm{SO}_{4}$ solution at room temperature for $24 \mathrm{~h}$. Then, the membranes were thoroughly cleaned with deionized water for an additional $72 \mathrm{~h}$ to remove any free $\mathrm{H}^{+}$and stored in deionized water for subsequent testing.

\subsection{Characterization techniques}

${ }^{1} \mathrm{H}$ NMR spectra, displayed in ppm, were obtained on a Varian $400 \mathrm{MHz}$ NMR spectrometer using tetramethylsilane as an internal standard and DMSO- $d_{6}$ as the solvent. Elemental analyses, including $\mathrm{S}$ determination, were carried out on a Vario EL elemental analyzer. $M_{\mathrm{W}}$ analysis was performed on a Waters HPLC 2695 instrument using dimethylformamide as the eluent and polystyrene as the standard sample. The melting points were determined on a model XT4A instrument. The thermal stability of the membranes was assessed on a TGA instrument (model: Q50) under nitrogen, with two flows of $40 \mathrm{ml} \mathrm{min}^{-1}$, over a temperature range of 50 to $600{ }^{\circ} \mathrm{C}$ at a heating rate of $10{ }^{\circ} \mathrm{C} \mathrm{min}{ }^{-1}$. Atomic force microscopy (AFM) phase images were obtained in tapping mode on a Bruker microscope. Proton conductivity was measured using an electrochemical impedance spectroscopy technique with a frequency range of $1 \mathrm{MHz}$ to $10 \mathrm{~Hz}$, and the ion exchange capacity (IEC) was measured via a classical titration method, for which detailed measurements have been reported in the literature. ${ }^{6}$

\subsection{Chemical oxidative degradation processes}

Chemical oxidative degradation was simulated in the environment of the PEMFC using Fenton's reagent (20 ppm $\mathrm{Fe}_{2} \mathrm{SO}_{4}$ in 
$3 \% \mathrm{H}_{2} \mathrm{O}_{2}$ ), which exposes the membrane to a highly oxidative environment. ${ }^{20}$ The well-known degradation test using Fenton's reaction is related to radicals as follows:

$$
\begin{gathered}
\mathrm{H}_{2} \mathrm{O}_{2}+\mathrm{Fe}(\mathrm{II}) \rightarrow \mathrm{Fe}(\mathrm{III})+{ }^{\cdot} \mathrm{OH}+\mathrm{HO}^{-} \\
\mathrm{Fe}(\mathrm{II})+\mathrm{O}_{2} \rightarrow \mathrm{Fe}(\mathrm{III})+{ }^{\cdot} \mathrm{O}_{2}{ }^{-} \\
\cdot \mathrm{OH}+\mathrm{H}_{2} \mathrm{O}_{2} \rightarrow \cdot \mathrm{OOH}+\mathrm{H}_{2} \mathrm{O}
\end{gathered}
$$

The membranes were cut into ten small pieces $(4 \times 1$ $\mathrm{cm}^{2}$ ). These specimens were separately soaked in Fenton's reagent for $0 \mathrm{~h}, 5 \mathrm{~h}, 10 \mathrm{~h}, 15 \mathrm{~h}, 20 \mathrm{~h}, 25 \mathrm{~h}, 30 \mathrm{~h}, 35 \mathrm{~h}, 40 \mathrm{~h}$, and $45 \mathrm{~h}$. Then, the specimens were repeatedly washed with deionized water and then soaked in deionized water for $5 \mathrm{~h}$ to remove any small molecules that formed during the chemical oxidative degradation processes. The whole film samples were tested to determine their proton conductivity and were also characterized by gel permeation chromatography (GPC), AFM, TGA, FT-IR, ${ }^{1} \mathrm{H}$ NMR and elemental analysis.

\section{Results and discussion}

\subsection{Characterization of the chemical structure}

The linear poly(arylene ether ketone) (Scheme 2) was synthesized and characterized. Detailed characterization of the polymers is shown in the ESI. $\uparrow$ The chemical structure of the samples treated with Fenton's reagent was also confirmed by ${ }^{1} \mathrm{H}$ NMR. Fig. 1 shows the ${ }^{1} \mathrm{H}$ NMR stacked spectra of the samples with their peak assignments. The spectra of the different samples agree well with that of the untreated polymers $(0 \mathrm{~h})$. After treatment with Fenton's reagent, if radicals first attacked the sulfonated groups (Section $\mathrm{C}$ ), the characteristic peak of $\mathrm{H}_{\mathrm{d}}$ (at $\sim 4.5 \mathrm{ppm}$ ) corresponding to the $-\mathrm{SO}_{3} \mathrm{H}$ group should disappear as the soaking time increased, particularly after membrane fragmentation. Alternatively, if radicals first attacked the alkyl side chains, the ratio of the representative proton signals $\left(\mathrm{H}_{\mathrm{a}}, \mathrm{H}_{\mathrm{b}}\right.$, and $\mathrm{H}_{\mathrm{c}}$ ) from the alkyl linker of Section $\mathrm{B}$ and the peak of $\mathrm{H}_{\mathrm{d}}$ should clearly change, even complete disappear after membrane fragmentation. However, no changes in the ${ }^{1} \mathrm{H}$ NMR spectra of the samples in terms of the characteristic peaks $\left(\mathrm{H}_{\mathrm{a}}, \mathrm{H}_{\mathrm{b}}, \mathrm{H}_{\mathrm{c}}\right.$, and $\left.\mathrm{H}_{\mathrm{d}}\right)$ were observed compared to that the untreated polymers $(0 \mathrm{~h})$ as the soaking time increased, even after membrane

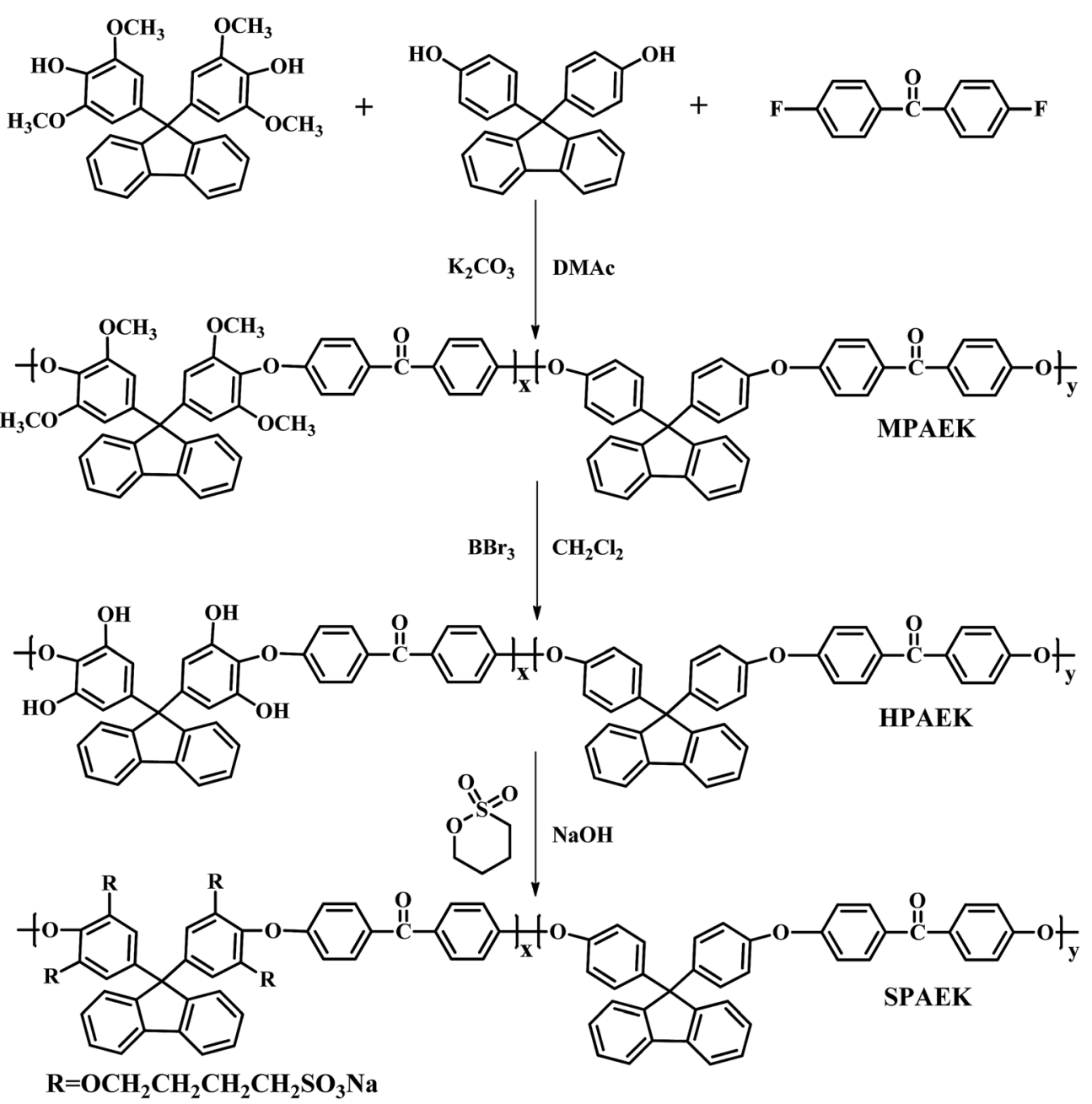

Scheme 2 Synthesis of the MPAEK, HPAEK and SPAEK copolymers. 




Fig. $1{ }^{1} \mathrm{H}$ NMR spectra of the sulfonated poly(aryl ether ketone) membranes.

fragmentation. Thus, Sections B and C retained stable chemical structures after treatment with Fenton's reagent.

To further understand the degradation process, the molecular structures of the membranes were verified by FT-IR, as shown in Fig. 2. The characteristic bands at 1047 and $1128 \mathrm{~cm}^{-1}$ ascribed to the $\mathrm{O}=\mathrm{S}=\mathrm{O}$ stretching vibration of the sulfonated groups indicate the presence of sulfonic acid groups. As the duration of immersion in Fenton's reagent increased, if the free radicals first attacked the sulfonic acid group or flexible alkyl side chains, the low $M_{\mathrm{w}}$ groups would be removed after washing the tested membrane with deionized water, and the IR spectral ratios of the $\mathrm{O}=\mathrm{S}=\mathrm{O}$ stretching vibration would change and even completely disappear. However, the $\mathrm{O}=\mathrm{S}=\mathrm{O}$ stretching vibration remained the same as that in the initial membrane with increasing immersion time (Fig. 2), and the alkyl side chains were close to the sulfonic acid groups. Comparison of the IR spectra ( $0 \mathrm{~h}, 35 \mathrm{~h}$ and $40 \mathrm{~h})$ indicated that the sulfonic acid groups and alkyl side chains were insensitive to the free radicals of the Fenton's reagent.

The main characteristic peaks in the ${ }^{1} \mathrm{H}$ NMR spectra and the characteristic bands in the FT-IR spectra remained approximately the same for all of the test samples. These results showed that the free radical attacks of the sulfonic acid groups (Section B) and alkyl side chains (Section B) are somehow limited compared to the free radical attacks on the polymer main chains (Section A).

\subsection{GPC and elemental analysis}

The $M_{\mathrm{w}}$, as a visual indicator, can reveal the structural degradation of the polymers. The GPC spectra of the SPAEKs

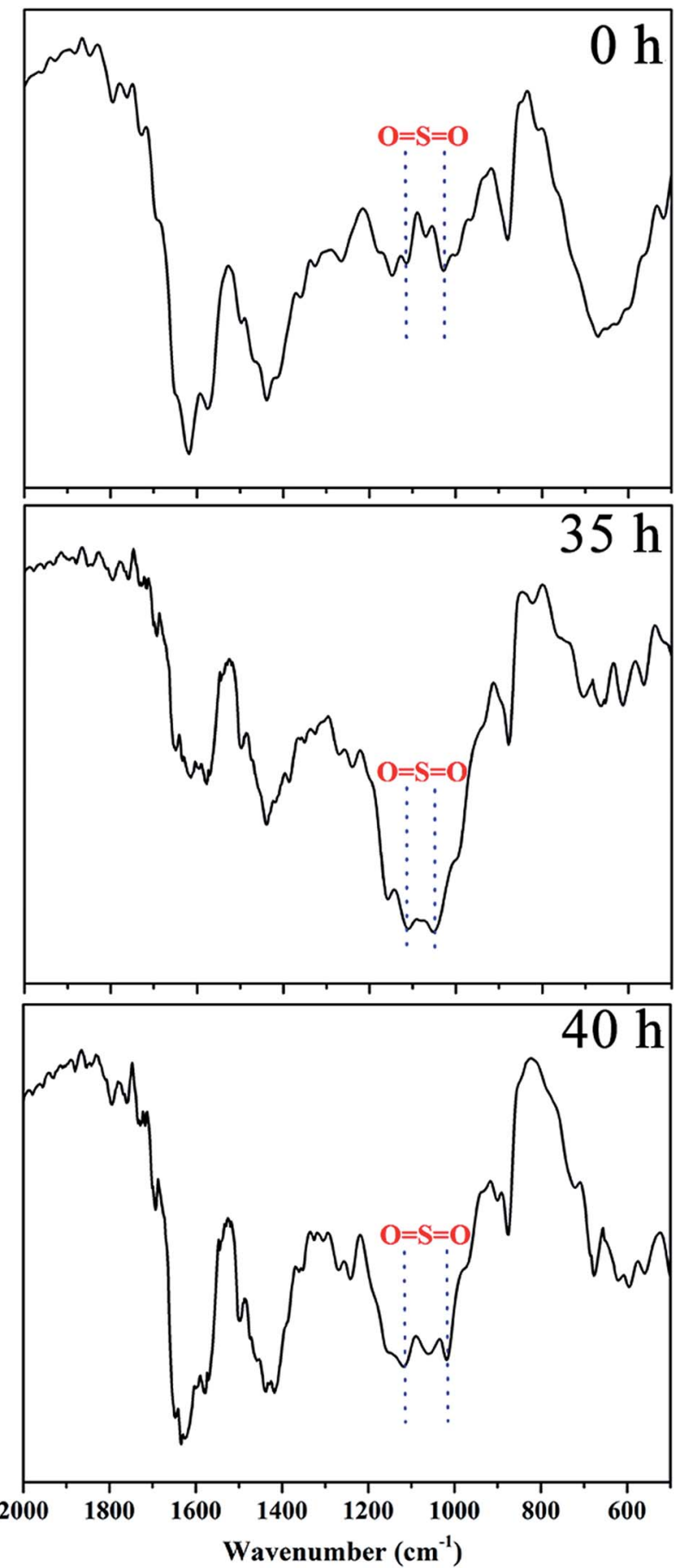

Fig. 2 FT-IR spectra of the sulfonated poly(aryl ether ketone) membranes.

measured after treatment with Fenton's reagent are shown in Fig. 3. The retention time of the SPAEKs increased with the soaking time in the Fenton tests, along with the appearance of small peaks in the low $M_{\mathrm{w}}$ range for the samples. Multiple peaks were clearly observed in the GPC chromatograms of the samples during degradation, suggesting that the $M_{\mathrm{w}}$ decreased gradually. The average $M_{\mathrm{w}}$ of each sample is shown in Table 1 . When the membrane was immersed in Fenton's solution, the $M_{\mathrm{w}}$ of the SPAEKs changed from 73400 to 30 200. Meanwhile, the 




Fig. 3 GPC spectra of the sulfonated poly(aryl ether ketone) membranes after treatment with Fenton's reagent.

average numbers $(x, y, x+y)$ of molecular units shown in Fig. 4 were calculated from the $M_{\mathrm{w}}$ determined by GPC and the elemental $\mathrm{H}$ percentage determined from the ${ }^{1} \mathrm{H}$ NMR spectra. After treatment with Fenton's reagent, all of the molecular units $(x+y)$ decreased gradually with the immersion time from 120 to 50 , indicating that great changes in the polymer main chain structure had occurred. If the radicals attacked on the alkyl side chains or sulfonic acid groups, a small average $M_{\mathrm{w}}$ should be obtained, and the average molecular units of the polymers should not significantly decrease, neither of which agree with the results of Fig. 4. Therefore, the cleavage of Section B or C had little impact on the $M_{\mathrm{w}}$, and the significant decrease in $M_{\mathrm{w}}$ may be ascribed to the cleavage of the main chain structure of SPAEKs.

The elemental composition of the SPAEKs was measured on a Vario elemental analyzer, and the results are shown in Table 1. The element $\mathrm{N}$ was detected because the solvent DMAc was used for membrane formation. The sulfonic acid groups of all the SPAEK samples contain $\mathrm{S}$, whereas the other structures do not contain S. After treatment with Fenton's reagent, the S content in the membrane decreased dramatically if the radicals attacked Section B or C. However, the S content in the SPAEKs decreased only slightly $(<20 \%)$ before the membrane broke $(35$ $\mathrm{h}$ ), and after the membrane broke, the $\mathrm{S}$ content remained high, indicating that there was no significant loss of sulfonic acid groups from any of the polymer compounds in the degradation tests. Therefore, most of the sulfonic acid groups were still grafted to the main polymer chains, and Sections B and C remained relatively stable during the chemical degradation of the SPAEKs.

After treating the polymers with Fenton's reagent, the polymers were characterized by GPC, ${ }^{1} \mathrm{H}$ NMR spectroscopy, and elemental analysis. Table 1 summarizes the degradation results for the number of $\mathrm{S}$ atoms, which were calculated using two methods: one involving GPC and ${ }^{1} \mathrm{H}$ NMR and another involving elemental analysis. However, the number of $\mathrm{S}$ atoms was essentially the same when calculated using entirely different methods at the same treatment time. Because a certain section of the polymer that was grafted to the alkylsulfonated side chains was lost, the content of S decreased; meanwhile, number of $\mathrm{S}$ atoms in the lost polymer section was close to the theoretical number of $\mathrm{S}$ atoms calculated from elemental analysis, indicating the possibility that only the polymer main chains were attacked by the free radicals during the entire degradation process.

The GPC and elemental analysis results showed that the entire degradation process of these polymers is primarily caused by the decrease in polymer $M_{\mathrm{w}}$ as a result of main chain scissions.

\subsection{Proton conductivity, IEC and thermal properties}

The effect of oxidative degradation on the proton conductivity and IEC of the membranes was studied carefully, as shown in Fig. 5. The membranes were immersed in Fenton's reagent, and the proton conductivity of the membranes was tested once every $5 \mathrm{~h}$. After every $5 \mathrm{~h}$ of immersion in Fenton's reagent, the membranes were taken out of the reagent, washed with deionized water, acidified with $1 \mathrm{M} \mathrm{HCl}$, and then analyzed.

Table 1 Summary of GPC and elemental analysis of the sulfonated poly(aryl ether ketone) membranes

\begin{tabular}{|c|c|c|c|c|c|c|c|c|c|}
\hline $\begin{array}{l}\text { Soaking time } \\
\text { (h) }\end{array}$ & $M_{\mathrm{w}}{ }^{a}\left(\times 10^{5}\right)$ & $x /(x+y)^{b}(\%)$ & $M_{\mathrm{wx}}^{c}\left(\times 10^{5}\right)$ & Number of S atoms ${ }^{d}$ & $\mathrm{~N}^{e}(\%)$ & $\mathrm{C}^{e}(\%)$ & $\mathrm{H}^{e}(\%)$ & $\mathrm{S}^{e}(\%)$ & $\begin{array}{l}\text { Number } \\
\text { of S atoms }\end{array}$ \\
\hline 0 & 7.34 & 21.46 & 1.58 & 55.73 & 0.10 & 69.19 & 4.171 & 2.480 & 56.89 \\
\hline 10 & 4.77 & 20.92 & 1.00 & 35.27 & 0.05 & 65.98 & 4.087 & 2.204 & 32.85 \\
\hline 15 & 4.24 & 21.19 & 0.90 & 31.75 & 0.06 & 67.95 & 4.195 & 2.283 & 30.25 \\
\hline 20 & 4.13 & 19.61 & 0.81 & 28.57 & 0.06 & 67.80 & 4.180 & 2.182 & 28.16 \\
\hline 35 & 3.05 & 19.16 & 0.58 & 20.46 & 0.06 & 69.10 & 4.152 & 2.013 & 19.17 \\
\hline 40 & 3.04 & 19.01 & 0.58 & 20.46 & 0.06 & 69.03 & 4.152 & 1.861 & 17.68 \\
\hline 45 & 3.02 & 21.46 & 0.55 & 19.40 & 0.06 & 69.54 & 4.110 & 1.661 & 15.68 \\
\hline
\end{tabular}

${ }^{a}$ Determined by GPC. ${ }^{b}$ Determined from ${ }^{1} \mathrm{H}$ NMR spectra. ${ }^{c} M_{\mathrm{wx}}=M_{\mathrm{w}} \times x /(x+y) .{ }^{d}$ Calculated from GPC and ${ }^{1} \mathrm{H}$ NMR spectra. ${ }^{e}$ Determined by elemental analysis. ${ }^{f}$ Calculated from elemental analysis results. 


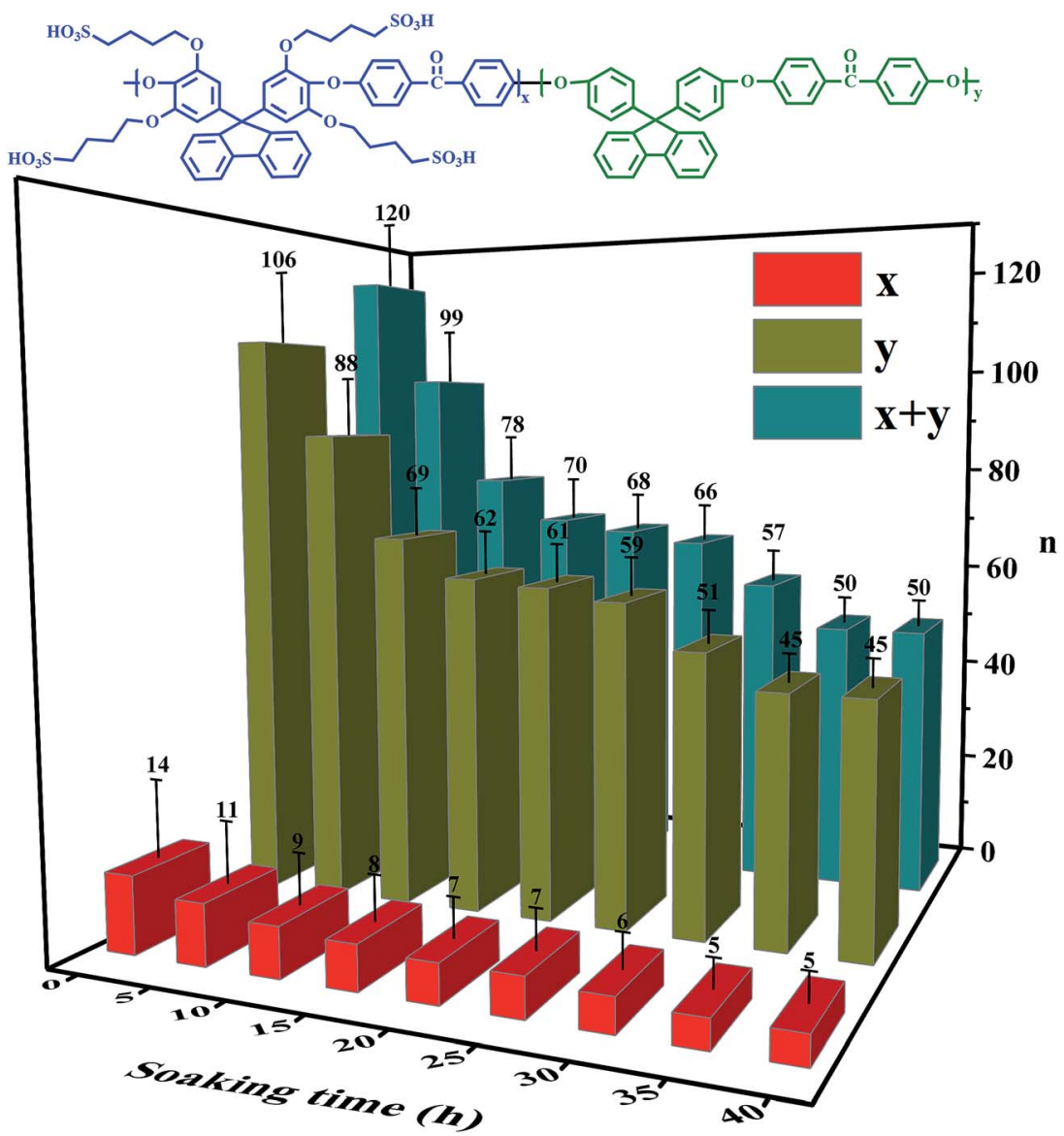

Fig. 4 Change in the molecular units of the sulfonated poly(aryl ether ketone) membranes.

Unfortunately, the membranes began to break into pieces after $35 \mathrm{~h}$ of immersion in Fenton's reagent, and the conductivity could no longer be obtained. Fig. 5(a) shows the relationship between the proton conductivity and immersion time in Fenton's reagent prior to $35 \mathrm{~h}$. The proton conductivity relies
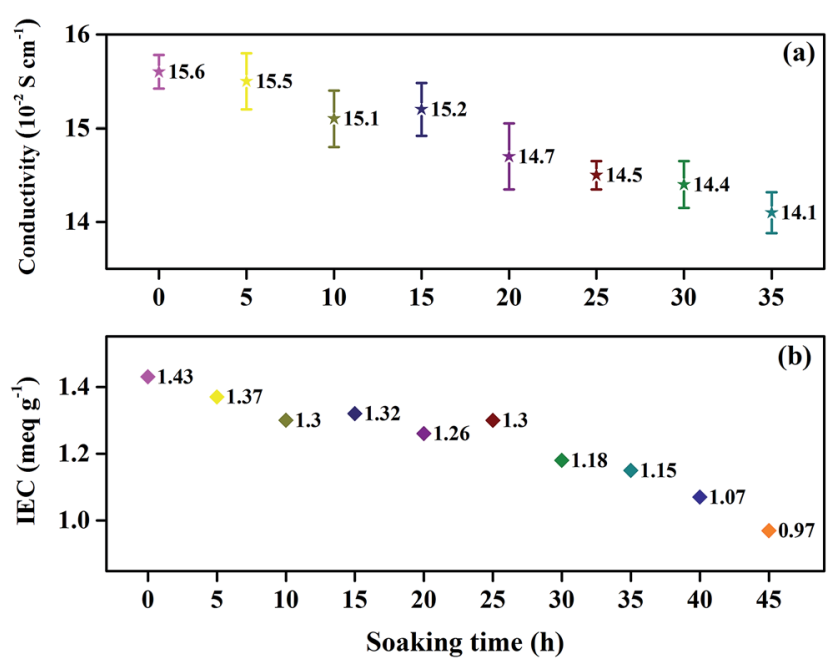

Fig. 5 Proton conductivity (a) and IEC (b) of the sulfonated poly(aryl ether ketone) membranes. heavily on the number of sulfonic acid groups in the electrolyte membranes. ${ }^{21}$ From Scheme 1, we can infer that the cleavage of Section B or C would obviously decrease the number of sulfonic acid groups, leading to a decrease in proton conductivity. However, the proton conductivity rate decreased slowly by less than $0.015 \mathrm{~S} \mathrm{~cm}^{-1}$ during the degradation of the membranes,

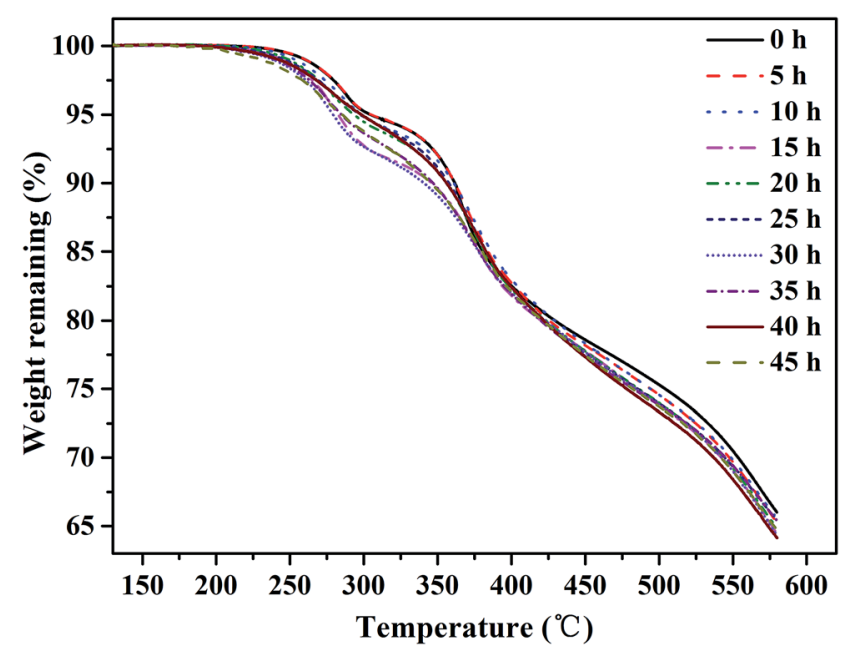

Fig. 6 TGA curves of the sulfonated poly(aryl ether ketone) membranes. 



Fig. 7 AFM phase images at $0 \mathrm{~h}, 35 \mathrm{~h}$ and $40 \mathrm{~h}$ of the sulfonated poly(aryl ether ketone) membranes.

which may have been attributed to the proton transport channels essentially remaining unchanged with the degradation of the membrane. As shown in Fig. 5(b), the IEC of the membranes exhibited a similar tendency as the proton conductivity as the soaking time increased, which further verified the relatively constant proton conductivity with membrane degradation. Therefore, Sections B and C were relatively stable against the attack of free radicals, agreeing with the elemental analysis results.

The thermal stability of the SPAEKs was assessed by TGA. The TGA curves of all SPAEKs are shown in Fig. 6. The distinct weight loss at $220-300{ }^{\circ} \mathrm{C}$ was assigned to the breakage of the alkylsulfonated side chains. All the curves ranging from 220 to $300{ }^{\circ} \mathrm{C}$ almost overlapped. These results also suggest that the apparent cleavage of the membrane after $35 \mathrm{~h}$ was not mainly caused by the alkylsulfonated side chains.

\subsection{Morphological analysis}

The phase morphologies of the SPAEKs $(0 \mathrm{~h}, 35 \mathrm{~h}$, and $40 \mathrm{~h})$ were investigated by AFM, and the results are shown in Fig. 7 . The dark region in the images represents the hydrophilic area of the SPAEK membranes (sulfonic acid moieties), and the bright region refers to the domain formed by hydrophobic polymer backbones (the main polymer chain). ${ }^{22,23}$ For SPAEK copolymers, the incorporation of flexible side chain sulfonic acid groups could be beneficial to the aggregation of ionic clusters, which would lead to more obvious hydrophilic/hydrophobic separation. The AFM phase images exhibit a clear nanophaseseparated morphology ${ }^{24}$ which indicates that the sulfonic acid groups had aggregated into small hydrophilic clusters that could provide proton transport channels or ionic transport pathways. During degradation, if the alkyl side chains or sulfonic acid groups were preferentially attacked, equivalent hydrophilic clusters would be lost, and the phase separation would gradually become faint. However, the phase separation became clearer with increasing immersion time. We propose that the main chain of the polymer was broken, and as a consequence, small segments of polymer containing sulfonic acid groups tended to aggregate in the large hydrophilic nanomicro region. Coinciding with the elemental results and proton conductivity results, the $\mathrm{S}$ content of the membrane at $35 \mathrm{~h}$ decreased by approximately $18.8 \%$, but the proton conductivity remained at a relatively higher conductivity. These results indicate that most of the free radicals attacked the polymer main chain after treatment with Fenton's reagent.

\section{Conclusion}

Highly stable and durable SPAEKs were successfully synthesized as PEMs, and the oxidative degradation process was investigated in detail through treatment with Fenton's reagent. The proton conductivity, ${ }^{1} \mathrm{H}$ NMR, FT-IR, and elemental analysis results suggest that the sulfonic acid groups remained relative stable during the Fenton's test. Moreover, the GPC results, TGA spectra and AFM spectra indicate that the main chains of the polymer were significantly disrupted during the degradation of the membranes. As a conclusion about the degradation process based on the current experimental data, the apparent structural degradation of the SPAEKs in Fenton's test is mainly ascribed to the cleavage of the main chains of the polymer (Section A in Fig. 1). Accordingly, the chemical stability of sulfonated poly (arylene ether ketone)s can be improved by increasing the stability of the main chain.

\section{Conflict of interest}

All authors declare no conflicts of interest.

\section{Acknowledgements}

We are very grateful for the financial support from the Nanshan District special funds (FG2013JNYF0015A), the National Basic Research Program of China (no. 2014CB643600), the Shenzhen Sci \& Tech research grant (JCYJ 20150331142303052, JCYJ201303291 05010137 and ZDSYS201507141105130) and the Natural Science Foundation of Guangdong Province (2015A030313546).

\section{References}

1 H. Zhang and P. K. Shen, Chem. Soc. Rev., 2012, 41, 23822394.

2 H. Zhang and P. K. Shen, Chem. Rev., 2012, 112, 2780-2832.

3 L.-C. Jheng, W. J.-Y. Chang, S. L.-C. Hsu and P.-Y. Cheng, J. Power Sources, 2016, 323, 57-66.

4 H. Xie, D. Tao, J. Ni, X. Xiang, C. Gao and L. Wang, J. Membr. Sci., 2016, 497, 55-66. 
5 M. K. Song, H. Li, J. Li, D. Zhao, J. Wang and M. Liu, Adv. Mater., 2014, 26, 1277-1282.

6 D. Liu, D. Tao, J. Ni, X. Xiang, L. Wang and J. Xi, J. Mater. Chem. C, 2016, 4, 1326-1335.

7 K. Oh, K. Ketpang, H. Kim and S. Shanmugam, J. Membr. Sci., 2016, 507, 135-142.

8 H. Xie, D. Liu, X. Xiang, C. Zhu and L. Wang, J. Mater. Sci., 2016, 51, 7119-7129.

9 S. Li, T. Higashihara, M. Ueda and T. Hayakawa, J. Polym. Sci., Part A: Polym. Chem., 2014, 52, 21-29.

10 N. Gao, F. Zhang, S. Zhang and J. Liu, J. Membr. Sci., 2011, 372, 49-56.

11 C. Wang, N. Li, D. W. Shin, S. Y. Lee, N. R. Kang, Y. M. Lee and M. D. Guiver, Macromolecules, 2011, 44, 7296-7306.

12 J. Maruyama, M. Inaba and Z. Ogumi, Electrochim. Acta, 1999, 45, 415-422.

13 C. Perrot, L. Gonon, M. Bardet, C. Marestin, A. Pierre-Bayle and G. Gebel, Polymer, 2009, 50, 1671-1681.

14 J. Lawrence and T. Yamaguchi, J. Membr. Sci., 2008, 325, 633640.
15 R. Uegaki, Y. Akiyama, S. Tojo, Y. Honda and S. Nishijima, J. Power Sources, 2011, 196, 9856-9861.

16 M. Aoki, H. Uchida and M. Watanabe, Electrochem. Commun., 2005, 7, 1434-1438.

17 G. Hübner and E. Roduner, J. Mater. Chem., 1999, 9, 409-418. 18 B. Mattsson, H. Ericson, L. Torell and F. Sundholm, Electrochim. Acta, 2000, 45, 1405-1408.

19 L. Sheng, T. Higashihara, M. Ueda and T. Hayakawa, J. Polym. Sci., Part A: Polym. Chem., 2014, 52, 21-29.

20 C. Mai, A. Majcherczyk, W. Schormann and A. Huttermann, Polym. Degrad. Stab., 2002, 75, 107-112.

21 Y. Lim, S. Lee, H. Jang, T. Hong, J. Yoo, J. Ha, D. Lee and W. Kim, Int. J. Hydrogen Energy, 2014, 39, 21613-21619.

22 N. Li, D. S. Hwang, S. Y. Lee, Y.-L. Liu, Y. M. Lee and M. D. Guiver, Macromolecules, 2011, 44, 4901-4910.

23 N. Li and M. D. Guiver, Macromolecules, 2014, 47, 2175-2198. 24 J. Y. Chu, A. R. Kim, K. S. Nahm, H.-K. Lee and D. J. Yoo, Int. J. Hydrogen Energy, 2013, 38, 6268-6274. 